
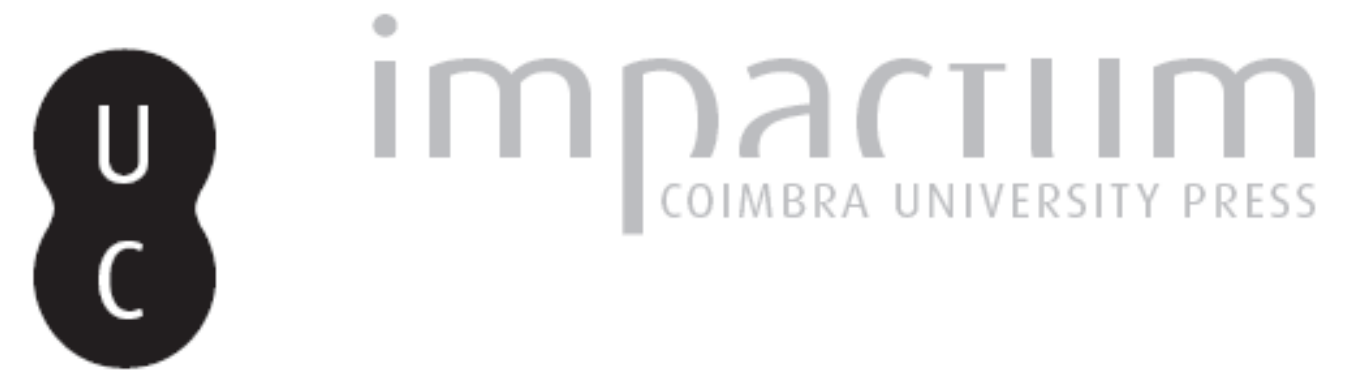

\title{
O simbolismo dos amuletos cardíacos no Antigo Egipto
}

\section{Autor(es): $\quad$ Sousa, Rogério}

Publicado por: Centro de História da Universidade de Lisboa

URL persistente:

URI:http://hdl.handle.net/10316.2/23718

DOI:

DOI:http://dx.doi.org/10.14195/0871-9527_20_6

Accessed : $\quad$ 26-Apr-2023 15:12:42

A navegação consulta e descarregamento dos títulos inseridos nas Bibliotecas Digitais UC Digitalis, UC Pombalina e UC Impactum, pressupõem a aceitação plena e sem reservas dos Termos e Condições de Uso destas Bibliotecas Digitais, disponíveis em https://digitalis.uc.pt/pt-pt/termos.

Conforme exposto nos referidos Termos e Condições de Uso, o descarregamento de títulos de acesso restrito requer uma licença válida de autorização devendo o utilizador aceder ao(s) documento(s) a partir de um endereço de IP da instituição detentora da supramencionada licença.

Ao utilizador é apenas permitido o descarregamento para uso pessoal, pelo que o emprego do(s) título(s) descarregado(s) para outro fim, designadamente comercial, carece de autorização do respetivo autor ou editor da obra.

Na medida em que todas as obras da UC Digitalis se encontram protegidas pelo Código do Direito de Autor e Direitos Conexos e demais legislação aplicável, toda a cópia, parcial ou total, deste documento, nos casos em que é legalmente admitida, deverá conter ou fazer-se acompanhar por este aviso.

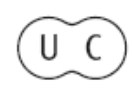




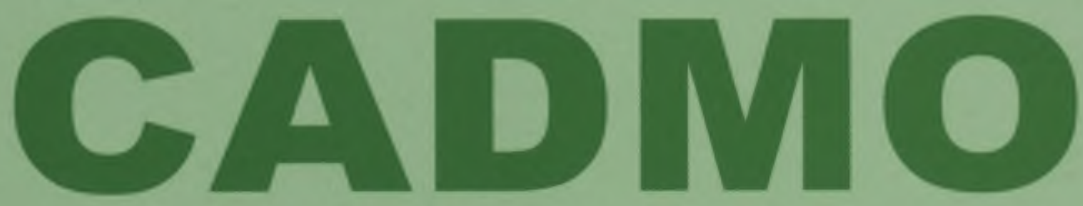

Revista de História Antiga

\author{
Centro de História \\ da Universidade de Lisboa
}

\title{
20
}

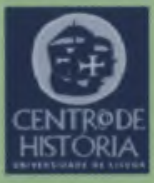

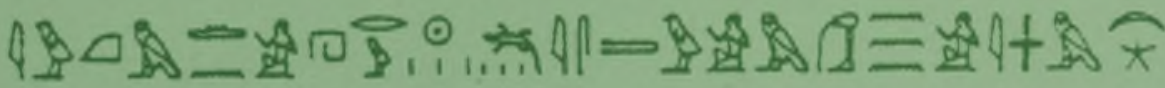

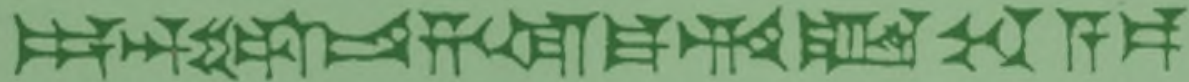

MHNIN AEI $\Delta$ E $\Theta E A ~ \Pi H \Lambda H I A \triangle E \Omega$ 


\title{
O SIMBOLISMO DOS AMULETOS CARDÍACOS NO ANTIGO EGIPTO(1)
}

\author{
ROGÉRIO SOUSA \\ Instituto Superior de Ciências da Saúde \\ solar.benu@gmail.com
}

As representações acerca do coração constituem um amplo campo de estudos da egiptologia que tem originado importantes contributos científicos, em especial a partir do estudo das fontes literárias. Neste domínio destacam-se as obras de Alexandre Piankoff ${ }^{(2)}$ e de Helmutt Brunner ${ }^{(3)}$ que, recorrendo aos métodos filológicos, delimitaram e isolaram algumas das mais importantes conotações semânticas dos termos cardíacos (sobretudo os termos ib e hati). Outros contributos originários da análise de fontes literárias específicas conduziram a uma caracterização muito criteriosa dos termos cardíacos. Destacamos, neste âmbito, o trabalho desenvolvido sobre os textos médicos ${ }^{(4)}$, que revelou uma caracterização do coração como uma realidade anatómica dual com um sentido muito mais amplo do que aquele que actualmente possui. Assim, para além do músculo do coração (hati), a anatomia egípcia entendia também como "coração", o interior do corpo evocado genericamente pela cavidade ventro-torácica (ib), pelo estômago (rá-ib) ou ainda pelos condutores (met) que conduziam, entre outras substâncias, o sangue. Do ponto de vista anatómico, o coração compreendia, portanto, um aspecto dinâmico (o músculo cardíaco, hatı), e um aspecto passivo (o interior $i b$ ), por onde circulava o sangue. $O$ hati e o ib, ou, dito de outra forma, o músculo cardíaco e o interior do corpo, podem, deste modo, ser vistos como aspectos complementares da mesma realidade anatómica, o coração, que assegurava a manutenção da vida. 
Os trabalhos desenvolvidos no âmbito dos textos sapienciais revelaram uma caracterização muito distinta do coração. Embora recorrendo aos mesmos termos anatómicos (ib e hati), o seu significado é manifestamente psicológico e permutável, não possuindo a delimitação rigorosa que apresenta nos textos médicos. Em todo o caso, nas fontes sapienciais o coração ${ }^{(5)}$ era entendido como a sede da consciência e, como tal, foi altamente valorizado para problematizar a responsabilidade individual na manutenção da maet(6). A associação entre o coração e a maet propulsionou a crescente complexificação desta noção, levando Jan Assmann a identificar três estádios na caracterização da responsabilidade pela integração cósmica do indivíduo ${ }^{(7)}$. Até ao Primeiro Período Intermediário, o autor considera que os textos de teor sapiencial revelam um homem guiado pelo coração do faraó, enquanto que, desde então e até ao início do Império Novo, se detecta a formulação de um homem guiado pelo seu próprio coração. A partir da XVIII dinastia, com especial intensidade a partir do período ramséssida, estamos perante o homem guiado pelo deus, que revela a sua presença divina a partir do coração do adorador.

Curiosamente, trabalhando com as mesmas fontes, nós próprios elaborámos, independentemente, uma formulação do desenvolvimento das representações literárias da noção de coração que apresenta o mesmo padrão ${ }^{(8)}$ : até ao Primeiro Período Intermediário, as fontes literárias interessam-se sobretudo pela caracterização do coração cósmico do faraó, o principal garante da maet. No Império Médio verifica-se uma "privatização" da responsabilidade maética, originando a caracterização do coração ouvinte, que não é mais do que a internalização da obediência ao faraó, o qual era identificado com a consciência do homem, a voz interior que o conduzia na vida para a realização da maet. A partir do Império Novo, prevalece a caracterização do coração amante, em que a realização da maet (até aí o principal atributo do coração nos textos sapienciais) é secundada pela manifestação interior da presença divina que se revela através do amor. Subjacente estava, portanto, a representação do coração como o templo interior do deus supremo e, concomitantemente, a celebração do seu divino poder sobre o macrocosmos (a criação) e o microcosmos (a vida humana).

Como referimos, estas representações do coração emanam sobretudo das fontes sapienciais, que são configuradas a partir das concepções que definem a religião egípcia no sentido lato que, no dizer de Jan Assmann, se prende essencialmente com a realização da maet ${ }^{(9)}$. Em continuidade com esta questão, mas qualitativamente diferente, a 
religião egípcia entendida em sentido estrito prende-se essencialmente com o culto prestado às divindades. Também neste domínio, por definição constelativo, ou seja, definido em função de um quadro mítico reactualizado por acções rituais, o coração desempenhava um papel decisivo. O culto, em particular, requeria uma transformação do coração que permitisse ao sacerdote flanquear as barreiras que separavam o real ordinário e o introduzisse diante do sagrado, onde poderia vislumbrar as divindades ${ }^{(10)}$. É à luz deste domínio específico (do culto e do ritual) que devemos entender as representações iconográficas e artísticas do coração.

A inegável riqueza das fontes literárias terá provavelmente facilitado o incipiente interesse despertado pelo estudo das representações do coração nas fontes iconográficas e artísticas, um vastíssimo campo que tem permanecido largamente por explorar ${ }^{(11)}$. Na sequência de um amplo inventário de ocorrências, levado a cabo sobretudo nas colecções do Museu do Louvre, do Museu Egípcio do Cairo e no Museu Egípcio de Turim, tivemos oportunidade de empreender, no âmbito da nossa tese de doutoramento, um estudo sistemático do amuleto cordiforme e das suas representações. Apresentamos neste artigo uma síntese do trabalho que desenvolvemos neste âmbito. Dadas as óbvias limitações editoriais que enquadram a apresentação deste texto, não nos poderemos alongar em demonstrações nem tão-pouco poderemos apresentar a documentação visual que tão necessária seria num estudo de carácter iconográfico. Remetemos o leitor interessado para a bibliografia já publicada ou, na sua ausência, para a consulta da nossa tese de doutoramento ${ }^{(12)}$.

Neste domínio de estudos, tão distinto dos métodos da filologia, não podemos confiar exclusivamente nas alusões explícitas de carácter textual, como aconteceria se o nosso objecto fosse a representação literária do coração. As representações do coração oriundas da arte e da iconografia têm um enquadramento mágico e ritual que as posiciona no domínio da religião egípcia que é regido por uma teologia implícita, ao passo que as referências literárias, sobretudo as oriundas da literatura sapiencial, apresentam o carácter "explicativo" próprio do domínio da teologia explícita ${ }^{(13)}$. Um estudo desta natureza deve necessariamente estar ciente do carácter implícito das representações iconográficas do coração e integrá-lo como um aspecto importante da sua metodologia. Mais do que limitar a pesquisa às fontes textuais, o estudo da iconografia cardíaca encontra no cruzamento das fontes as ferramentas decisivas para delimitar o significado dos sím- 
bolos associados ao coração, nomeadamente através da comparação criteriosa de símbolos, da sua confrontação com fontes textuais e com os dados arqueológicos disponíveis, que frequentemente nos proporcionam uma visão contextual mais alargada. Desse modo é possível compensar a ausência de referências textuais explícitas de carácter explicativo e ensaiar uma reconstituição de sentido que será sempre provisória e de carácter probabilístico.

\section{A tipologia dos amuletos cordiformes}

A primeira dificuldade que sentimos ao tentar sistematizar os dados recolhidos nos registos museológicos relativos aos amuletos cordiformes prende-se com a falta de dados precisos relacionados com a sua proveniência. Constituídas num tempo em que a arqueologia pouca atenção dava aos "objectos menores", as grandes colecções museológicas são pouco úteis para fornecer dados relacionados com a proveniência e a datação, e é nos próprios relatórios de escavação das missões arqueológicas que estas informações podem ser encontradas. Apesar desta limitação, para empreender um estudo formal, as colecções museológicas dão um aporte decisivo. Com mais de setecentos objectos inventariados, constituímos uma amostra muito significativa para desenvolver com segurança um estudo formal destes objectos.

O primeiro desafio a enfrentar quando estamos perante uma grande diversidade de variações formais de um objecto consiste em criar uma tipologia. Ao analisar as raras tipologias do amuleto cordiforme existentes verificámos que estas se regiam tanto por categorias simbólicas, como por categorias formais, o que não conduz a categorias mutuamente exclusivas. Quando confrontado com esta tarefa, o investigador deverá também ter o que se pode chamar um sentido "taxonómico", ou seja, deve evitar criar categorias prévias que julga serem pertinentes para a compreensão do objecto, cunhando-o assim com conotações semânticas que efectivamente pode não possuir. Flinders Petrie, por exemplo, baseando-se na identificação (correcta) entre o amuleto cordiforme e o hieróglifo ib (F 34) coloca o amuleto entre os objectos representativos de órgãos humanos ou animais ${ }^{(14)}$. No entanto, como veremos, tal identificação é errónea, uma vez que se baseia mais nas nossas próprias representações anatómicas do coração do que nas representações egípcias, e naturalmente induz, por si só, um conjunto de pressuposições de ordem semântica acerca 
do significado simbólico do próprio objecto. Efectivamente, decorrente deste viés interpretativo, não é raro ver atribuído ao amuleto cordiforme a função de constituir um substituto mágico do músculo cardíaco(15). Pela nossa parte, a partir do estudo que fizemos, não nos foi possível corroborar este tipo de interpretação, embora fossem essas, efectivamente, as expectativas iniciais.

A nossa primeira preocupação, ao analisar o conjunto de amuletos cordiformes, foi a de detectar no objecto estruturas formais que nos ajudassem a criar categorias mutuamente exclusivas. Foi assim que eliminámos as projecções laterais e a forma do corpo do amuleto como elementos morfológicos relevantes para proceder a essa classificação. Pelo contrário, a forma do bordo superior do amuleto e, quando existe, a decoração do topo do amuleto, afiguraram-se como elementos decisivos para assegurar uma diferenciação formal dos objectos. Já publicámos na revista Cadmo um artigo alusivo a esta matéria, pelo que não nos alongaremos neste domínio particular da nossa pesquisa ${ }^{(16)}$. Interessa-nos apenas referir que, no que toca à classificação do bordo do amuleto, três grandes categorias foram identificadas para a identificação de amuletos cordiformes simples:

Amuleto cordiforme de tipo vaso - apresenta a configuração geral do vaso nu e apenas se distingue destes pela inclusão de projecções laterais que assinalam os condutores met (vasos condutores que identificam com a actual noção anatómica de vasos sanguíneos). Apresenta em geral pequenas dimensões. É o tipo dominante de amuletos cordiformes simples até à Época Baixa.

Amuleto cordiforme de tipo pêndulo(17) - não apresenta qualquer bordo no topo do objecto. A sua configuração geral lembra a de um pêndulo usado nas balanças até ao período ramséssida. Este tipo de objecto assinala fortemente a associação simbólica do amuleto cordiforme ao imaginário da psicostasia. Apresenta, em geral, grandes dimensões.

Amuleto cordiforme de tipo cornija - apresenta um bordo quadrangular, por vezes muito destacado do corpo do amuleto através de um "pescoço" alongado. O resultado é a criação de uma cornija, semelhante à de um relicário, sobre o corpo do amuleto. Apresenta, em geral, pequenas dimensões. É o objecto dominante a partir da Época Baixa. 
Os amuletos cordiformes compósitos exibem um símbolo no topo do amuleto:

Amuleto cordiforme com cabeça humana - muito frequente no período ramséssida. Representa o defunto com a cabeleira tripartida própria de um deus justificado e testemunha a associação simbólica do amuleto cordiforme ao imaginário simbólico da psicostasia.

Amuleto cordiforme com cabeça de animal - é um tipo de objecto muito raro. As ocorrências elencadas por nós situam a sua produção entre o período ramséssida e o Terceiro Período Intermediário. Embora outras ocorrências possam ainda vir a ser identificadas, registámos, nos três exemplares elencados, a ocorrência da cabeça de falcão, babuíno e de cão selvagem, o que nos pode remeter para a identificação destes objectos com os vasos de vísceras encimados pelas cabeças dos quatro filhos de Hórus. Assim o amuleto com cabeça de falcão representaria Kebehsenuef, o amuleto com cabeça de babuíno evocaria Hapi e o objecto encimado pela cabeça de canídeo seria uma evocação de Duamutef. Mediante esta possibilidade, alguns vasos encimados com cabeça humana podem, deste modo, ser vistos como uma miniatura de Imseti. Esta associação pode relacionar-se com o facto de os vasos de vísceras se destinarem a acolher os órgãos do coração ib.

Amuleto cordiforme com disco solar - é encimado por um disco solar que normalmente se ergue sobre uma cornija. É um objecto raro, com alguma prevalência no Terceiro Período Intermediário, e, possivelmente, na Época Baixa.

\section{Uma perspectiva diacrónica do uso do amuleto cordiforme}

O cruzamento dos dados arqueológicos com os dados iconográficos levou-nos a identificar flutuações no uso ritual e na interpretação simbólica do amuleto cordiforme. As fontes iconográficas sugerem que o objecto começou por ser utilizado, no início da XVIII dinastia, pelos príncipes reais, e até pelo próprio faraó, como símbolo de pureza e de legitimidade real. Após o reinado de Hatchepsut, talvez com o intuito de cimentar a aliança entre o faraó e a elite administrativa, o amuleto cordiforme é representado na necrópole tebana sobretudo 
como um importante símbolo de sabedoria ${ }^{(18)}$. Nestas representações, o amuleto cordiforme (normalmente pintado de amarelo ou de encarnado, apresentando a configuração do amuleto cordiforme de tipo vaso), figura como uma condecoração real que assinalava a confiança depositada pelo faraó no funcionário. Em suma, o objecto assinalava o funcionário com um estatuto especial e provavelmente indicava que ele fazia parte de um círculo restrito de homens da confiança do faraó. No plano material, o amuleto do coração era confeccionado com a forma de um vaso (por vezes ocado) decorado frequentemente com a cartela real. Em pedra ou em ouro, este objecto luxuoso apresenta, evidentemente, uma ocorrência bastante ocasional na arqueologia egípcia.

Após o período amarniano, o amuleto cordiforme é utilizado sobretudo como uma condecoração usada pelo defunto no tribunal de Osíris. Um tal uso indica que a sua função não era a de substituir o músculo do coração, como habitualmente se sugere, mas sim a de representar o coração puro, maético, que havia sido pesado, com sucesso, na balança da psicostasia. O amuleto cordiforme, normalmente pintado de negro ou de azul-escuro, representava, portanto, a identidade "osíriaca" do defunto justificado. Como tal, várias versões do amuleto foram elaboradas, todas claramente vocacionadas para o horizonte funerário.

Durante a Época Baixa, o amuleto cordiforme tornou-se um atributo característico dos deuses infantis e juvenis, detectando-se uma grande mudança na leitura do objecto. Desde então, o objecto passou a gozar de uma grande popularidade e a ser usado sobretudo na vida terrena, certamente com intuitos apotropaicos. Concomitantemente, o objecto mudou de forma e adoptou a configuração de uma cornija idêntica à de um relicário.

\section{Constelações mitológicas associadas ao amuleto cordiforme}

Constituindo um objecto apotropaico, usado portanto com intuitos mágicos, a utilização do amuleto cordiforme era enquadrada por uma acção de carácter ritual que necessariamente era interpretada à luz de uma certa constelação simbólica. O simbolismo deste objecto apresenta, portanto, variações de significado em função da constelação mitológica que evoca. Apresentamos em seguida as principais constelações mitológicas que enquadravam a acção ritual do amuleto cordiforme. 


\section{O amuleto cordiforme no ciclo mitológico de Hórus}

Curiosamente, o amuleto cordiforme constitui um dos atributos divinos do deus Hórus, especialmente na sua forma aviária. Neste contexto, o amuleto cordiforme é habitualmente encimado por um disco solar, que assinala a identificação do coração de Hórus com o disco solar que garante a ordem cósmica. O mito da vitória de Hórus sobre Set constitui, por excelência, o mito fundador da ordem cósmica, e, neste contexto, o amuleto cordiforme encimado pelo disco solar parece evocar o triunfo de Hórus e a iluminação do seu coração que garante o equilíbrio cósmico. A capacidade de Hórus para garantir a conectividade cósmica e o equilíbrio entre as Duas Terras parece assim residir no seu coração solar. Talvez por essa razão, também o faraó, enquanto incarnação terrena de Hórus, usava o amuleto cordiforme encimado pelo disco solar. Um tal objecto deve ser entendido como uma representação do coração de Hórus e como um símbolo de sua vitória sobre Set, ou, por outras palavras, como um símbolo do poder conectivo de Hórus para instalar a vida e a maet.

Também os amuletos cordiformes feitos em ouro parecem animados com uma intencionalidade idêntica. Os amuletos do coração de ouro, por vezes inscritos com a cartela real, eram provavelmente usados como condecoração real, como um símbolo da obediência (interior) ao rei. Um objecto deste tipo poderia ser entendido como a expressão do ideal político antes de "estar no" coração do faraó. Desta forma, um funcionário que tenha sido alvo desta condecoração podia ser visto como um aliado de Hórus no seu combate contra Set, assinalando simultaneamente a sua obediência ao rei. Esta lealdade seria entendida como a capacidade de seguir o comando do coração. Obviamente, essa leitura mítica do poder conectivo do amuleto do coração é predominante no contexto da vida terrena.

\section{O amuleto cordiforme no ciclo mitológico de Osíris}

As fontes iconográficas, na sua maioria originárias da necrópole tebana, sugerem que o amuleto do coração estava estreitamente associado à pesagem do coração, especialmente ao longo do período ramséssida. Esta associação foi tão forte que, durante a XXI dinastia, o amuleto do coração parece mesmo ter sido usado como a peça central de todo um conjunto de rituais funerários, em especial no con- 
texto do túmulo coletivo dos sacerdotes de Amon encontrado em Deir el-Bahari(19). Parece bastante plausível que uma cerimónia de consagração do amuleto do coração poderá ter ocorrido no contexto dos rituais fúnebres, a fim de evocar a justificação do defunto e assinalar a sua vitória sobre Set. Em certas representações, esse ritual de consagração do amuleto cordiforme é apresentado como um banho lustral. Neste contexto, o amuleto simbolizava a pureza, a virtude e a dignidade restaurada de Osíris.

A associação entre o amuleto cordiforme e as crenças relacionadas com a pesagem do coração foi tal que inspirou a criação de tipos específicos de amuletos coração(20). Como um símbolo de pureza do coração, o amuleto era um sinal da vitória de Osíris sobre Set. Enquanto tal, o amuleto do coração foi também representado no peito dos inimigos do Egipto para ilustrar a punição de Set e a vitória de Osíris sobre a morte.

\section{O amuleto cordiforme no ciclo solar}

No ciclo solar, o amuleto do coração era interpretado como um salvo-conduto que abria o caminho do defunto para uma viagem de mudança e de renascimento. Simbolizando o poder da virtude e do conhecimento, o amuleto protegia o defunto durante a sua viagem pela Duat e mantinha-o a salvo dos ataques dos demónios do Além. $\mathrm{Na}$ posse do amuleto do coração, o defunto podia entrar nas regiões mais misteriosas do mundo inferior, para aí ser regenerado à imagem do percurso nocturno do deus Sol(21). O significado funerário do ciclo solar requeria o retorno ao ventre da grande mãe cósmica e um regresso à origem. A divindade que presidia a este ciclo era Nut, a deusa celestial que acolhia o defunto no seu ventre.

A possibilidade de entrar no útero da deusa cósmica dependia, no entanto, da justificação alcançada no tribunal de Osíris. Como tal, o amuleto do coração simbolizava o acesso do defunto ao ventre cósmico da deusa mãe que the facultava a desejada regeneração e renascimento. Ao longo da Época Baixa, é este o sentido mais prevalente do amuleto do coração que é usado principalmente como um atributo da criança solar, regenerada pela deusa mãe. Neste contexto, o objecto tornou-se no símbolo da protecção de ísis (mas também Hathor ou Neit) e o reflexo da relação pessoal entre o homem que o usa (identificado com a criança divina) e a deusa mãe. 
Embora tardia, a prevalência desta imagem feminina parece ter estado sempre implícita desde as primeiras ocorrências do amuleto do coração, uma vez que a própria configuração do amuleto cordiforme derivou do vaso $n u$, o vaso sagrado de Nut, conotado com a pureza e a vida.

\section{O simbolismo do escaravelho do coração}

Como vimos, em nenhum dos contextos simbólicos anteriormente referidos se detecta a leitura simbólica que habitualmente é atribuída ao amuleto cordiforme, sobretudo nas suas versões funerárias, que consistiria em ser um substituto mágico do músculo cardíaco e portanto figurar como uma espécie de "coração hati» confeccionado para a eternidade. Efectivamente detectámos que, sobretudo no contexto funerário, o amuleto do coração era efectivamente dado ao defunto, não como um substituto do órgão cardíaco, mas sim como uma condecoração dada pelo tribunal de Osíris para assinalar a sua pureza e sabedoria.

Surpreendentemente, é um outro amuleto cardíaco que parece ter cumprido esta função: o escaravelho do coração(22). A inscrição do capítulo 30 B do "Livro dos Mortos" (que procurava garantir o testemunho favorável do coração no tribunal de Osíris) na base do escaravelho do coração é frequentemente apresentada como o principal argumento para atribuir a este objecto a responsabilidade mágica de assegurar um resultado positivo na pesagem do coração.

Contradizendo esta leitura dos dados, as fontes iconográficas não mostram que o escaravelho do coração tenha desempenhado qualquer papel significativo nas vinhetas da pesagem do coração, em contraste com o amuleto do coração, cuja presença é bastante frequente e importante. Na verdade, embora obviamente o capítulo $30 \mathrm{~B}$ do "Livro dos Mortos" pudesse oferecer protecção contra o testemunho negativo do coração na psicostasia, a função mágica do escaravelho do coração não pode ser confundida com a do texto que apresenta. Frequentemente, na produção de amuletos, a colocação de inscrições ou de símbolos em certos objectos funciona como um meio de reforçar o seu papel mágico e não se confunde necessariamente com a sua intencionalidade mágica fundamental ${ }^{(23)}$. Pelas razões que apontaremos em seguida, a função do escaravelho do coração como potencial substituto do músculo cardíaco e, acima de tudo, como um símbolo de renascimento, parece ser muito mais decisiva. Efectiva- 
mente, mais do que no texto que o acompanha, para estimar a nossa compreensão do simbolismo deste objecto, devemos, em primeiro lugar, deter a nossa atenção no seu símbolo mais evidente, a forma de escaravelho que evoca o deus Khepri ("O que se transforma" ou "O que se manifesta"), o deus do Sol nascente ${ }^{(24)}$. O simbolismo do amuleto remete portanto para a ressurreição. Assim a sua função primordial seria certamente a de promover a identificação entre o órgão cardíaco e o deus do Sol nascente, a fim de assegurar o despertar dos mortos para uma vida nova.

Esta interpretação é reforçada pelas variações formais do escaravelho do coração. Os exemplares mais antigos de escaravelhos do coração conhecidos remontam à XIII dinastia e apresentam uma face humana desenhada sobre o protórax do insecto(25). Outros, oriundos do período ramséssida, apresentam uma cabeça humana(26). Na iconografia egípcia, as formas compósitas subordinam-se entre si numa relação que privilegia a cabeça. A cabeça assinala a identidade do ser representado enquanto o corpo tende a constituir uma "forma" que essa entidade escolhe para se manifestar. O escaravelho do coração com cabeça humana assinala simbolicamente que o defunto se manifesta sob a forma do Sol nascente, identificado com Khepri.

Como devemos então interpretar a inscrição do capítulo $30 \mathrm{~B}$ na base do escaravelho do coração? Uma vez mais devemos pensar em função dos dados que possuímos e, no caso deste objecto, também a iconografia do "Livro dos Mortos" reforça a ligação entre o capítulo 30 B e o escaravelho do coração, uma vez que o coleóptero sagrado constitui a vinheta mais comummente usada para ilustrar o texto. No entanto, é notório que o capítulo 30 B se integra numa sequência de textos que não remete para o julgamento dos mortos, como seria de esperar se a função deste texto fosse estritamente relacionada com a psicostasia. Pelo contrário, essa é a intenção do capítulo 125. O propósito mágico dos capítulos "cardíacos" (capítulos 26-30), em que o capítulo $30 \mathrm{~B}$ se insere, consiste em assegurar o "despertar" do coração ${ }^{(27)}$. A intenção mágica do capítulo $30 \mathrm{~B}$ consiste pois em «limpar» a memória conservada no coração do defunto, precisamente no momento em que este desperta. Desse modo preparava-se o coração para a psicostasia que, não obstante, se situava num momento ainda longínquo.

Além deste objectivo principal, parece plausível que o escaraveIho do coração realizasse outras funções relacionadas com as fases da viagem do falecido no mundo inferior. Na verdade, as rubricas dos 
capítulos 64 e 148 também afirmam que estes capítulos deviam ser lidos durante a deposição do escaravelho do coração na múmia. A temática da psicostasia parece estar novamente ausente neste elenco, já que o capítulo 125, o texto mais importante acerca do julgamento do defunto, uma vez mais não é associado ao escaravelho do coração. Também é interessante constatar que os capítulos 64 e 148 não parecem ter sido seleccionados aleatoriamente. $\mathrm{Na}$ verdade, cada um destes textos parece representar um ciclo temático no âmbito da viagem do defunto na vida do Além. O capítulo $30 \mathrm{~B}$, como já referimos, não está associado à psicostasia, mas sim à reanimação da múmia. O capítulo 64 marca o início da peret em heru, a "saída para o dia". Da mesma forma, o capítulo 148 destaca-se como um ponto de viragem no percurso do defunto no Além, uma vez que é a partir daí que ele penetra nas regiões mais interiores do templo de Osíris na Duat. O importante é que todos estes momentos críticos na vida do defunto tenham sido colocados sob a protecção mágica do escaravelho do coração. Afinal todos eles convergiam para o renascimento do defunto sob a forma de Khepri, o Sol nascente, figurado precisamente no próprio objecto.

\section{O valor hieroglífico e mágico dos amuletos cardíacos}

Ao contrário do escaravelho do coração, que era utilizado exclusivamente no contexto funerário, o amuleto do coração parece ter sido concebido sobretudo para um uso terreno. Tal não obstou obviamente a que os amuletos cordiformes tivessem sido incluídos entre o equipamento mágico da múmia, ou que, em certos períodos historicamente bem determinados, versões exclusivamente funerárias do objecto tivessem sido elaboradas, sobretudo com o propósito específico de assinalar o resultado positivo que se esperava obter na psicostasia. As duas categorias de objectos possuíam portanto um âmbito de aplicação distinto que importa clarificar recorrendo, em primeiro lugar, à explicitação do seu valor hieroglífico.

\section{$\mathrm{O}$ amuleto cordiforme e o termo ib}

Sabemos que a maioria dos amuletos egípcios podem ser vistos como versões tridimensionais de certos hieróglifos, como é o caso, só 
para mencionar alguns exemplos, dos amuletos ankh, djed, ou udjat. Também o amuleto de coração deve ser entendido como uma versão tridimensional do hieróglifo ib (F 34), que representa o coração de um touro. No entanto, como já referimos, esta atribuição pode levar-nos a uma interpretação errónea do seu intuito mágico, já que induz à identificação entre o amuleto do coração $(i b)$ e o músculo cardíaco, o qual, na verdade, era evocado pelo termo hati. Se usarmos a definição anatómica dos termos cardíacos (ib e hati) proposta por Thierry Bardinet, já anteriormente evocada nestas linhas, o termo ib evoca o interior do corpo onde os condutores met (tais como as veias) desempenham um papel crucial, enquanto que o termo hati evoca o músculo cardíaco. Esta é uma distinção crucial que deve guiar o nosso entendimento do valor hieroglífico dos amuletos cardíacos.

Seguindo esta atribuição, o amuleto do coração deve ser entendido como uma representação do coração $i b$, ou seja, o interior do corpo que os condutores met alimentam através do sangue. As projecções laterais, tão típicas dos amuletos do coração, representam, portanto, os condutores met e constituem o traço distintivo do coração ib evocado pelo amuleto cordiforme.

De acordo com o que o próprio Thierry Bardinet sugere, a natureza difusa e multifacetada do coração ib dificultava a sua representação hieroglífica enquanto entidade anatómica autónoma. Isso explica, nas suas palavras, que o termo ib tenha sido redigido recorrendo à imagem do músculo cardíaco (o coração hati, portanto) que era na realidade o centro de onde irradiavam os condutores met. ${ }^{(28)}$ Assim, embora pareçam insignificantes, as projecções laterais dão ao amuleto do coração o seu real significado, uma vez que representam a função conectiva dos condutores met. Esta leitura fortemente anatómica do amuleto não deve excluir a interpretação do seu sentido mental ou sapiencial. Tal como o próprio termo $i b$, o significado preponderante do amuleto do coração deve ser focado no sentido «mental» e psicológico. Neste plano, o amuleto simbolizava o poder de integração cósmica do coração ib, graças à sabedoria e à prática da maet. É provavelmente por essa razão que, sobretudo nos primeiros exemplares dos amuletos cordiformes, desafiando as convenções naturalistas, o vaso sagrado $n u$, evocativo da deusa Nut, tenha sido combinado com as projecções laterais evocativas dos condutores met, para representar o papel receptivo do coração $i b$. A representação do coração $i b$ como um vaso era aliás um topos recorrente da literatura sapiencial egípcia, e estava em linha com a identificação do coração ib com a 
cavidade gástrica (rá-ib). Na literatura egípcia, as alusões ao coração ib como um recipiente abundam. "Estar dentro do coração ib" significa "ser amado", ou ser "alguém de confiança". Na autobiografia de Uni, por exemplo, o governador do Alto Egipto durante o reinado de Pepi I, dizia que: «Eu enchi o coração ib do faraó com as minhas virtudes "(29). Metáforas deste tipo mostram claramente que as funções mentais do coração ib eram definidas por meio da representação do coração como um vaso, portanto algo vazio em essência que tinha a capacidade para ser repleto de emoções e de conhecimento. Os conselhos para "colocar os livros no coração ib" são disso testemunho. ${ }^{(30)}$ A associação iconográfica com o vaso nu foi talvez a melhor maneira de evocar a principal função do coração ib que era, no fundo, a de ser receptivo.

O amuleto do coração apresenta, portanto, uma forte influência do valor literário e anatómico do termo ib. Além disso, o objecto evoca a função do coração ib combinando o valor hieroglífico do vaso nu com a dos condutores met. Através desta combinação, o amuleto do coração evocava, no plano anatómico, o poder de vida garantido pelo sangue que corre nas veias (os condutores met), ao passo que, no plano mental, evocava a integração cósmica garantida pelo coração $i b$, uma vez repleto de sabedoria. Garantir a vida e a integração cósmica (os conceitos são de resto redundantes no antigo Egipto) graças à pureza e à sabedoria eram, portanto, as principais funções mágicas garantidas pelo amuleto cordiforme.

\section{O escaravelho do coração e o termo kheper}

Já aqui foi referido que o simbolismo do escaravelho do coração deve procurar-se naquele que é o seu traço mais saliente: a sua forma de escaravelho evocativa do deus Khepri. No entanto, o escaraveIho é também o signo hieroglífico kheper, "transformar", "vir à existência", ou ainda "manifestação", ou "forma". Não será certamente por acaso que no capítulo 30 B no "Livro dos Mortos", o coração hati é explicitamente associado às "manifestações", kheperu, do defunto:

Ó, meu coração ib de minha mãe, ó, meu coração ib de minha mãe! Ó, meu coração hati das minhas transformações (kheperu)! Não te ergas contra mim como testemunha. Não te oponhas a mim no tribunal! $(\ldots)^{(31)}$ 
À luz da natureza mágica do texto, podemos admitir que os termos ib e hati se refiram aos amuletos cardíacos. Uma vez que os textos do "Livro dos Mortos" acompanhavam o ritual funerário, as alusões aos termos ib e ao hati não devem ser entendidas como considerações de carácter médico ou literário, mas sim como referências aos amuletos cardíacos que, nesta etapa do ritual funerário, eram efectivamente oferecidos à múmia. Afinal não devemos esquecer que o termo ib é explicitamente usado no capítulo 29 B para designar o amuleto do coração. Se a correspondência entre o termo ib e o amuleto cordiforme é, neste momento, perfeitamente clara, importa ainda esclarecer, tanto quanto nos é possível, a relação entre o coração hati e o escaravelho (kheper). Antes do mais, temos de clarificar que o termo hati significa literalmente "O que está ao comando". Trata-se, portanto, da evocação, no plano corporal, da função activa e dinâmica do músculo cardíaco, "que está ao comando" do corpo. Do mesmo modo, no plano anímico, o termo hati era preferencialmente associado à manifestação da vontade individual que comanda a acção do indivíduo sobre a terra. Na vida do Além, é natural que a sede da vontade individual, o coração hati, se identificasse com o criador, o que é, de resto, evocado no capítulo 27 . Nesta óptica, o escaravelho do coração constituía a representação do coração hati transformado do defunto, que literalmente se "manifesta" sob a "forma" do deus Khepri, "O que vem à existência".

A colocação do escaravelho do coração na múmia revela também que era intenso o desejo de proximidade entre o objecto e o músculo cardíaco, o que, mais do que qualquer outro dado, nos deve alertar para outra importante mágica do objecto, que era certamente a de constituir o substituto do músculo cardíaco. Por outras palavras, o escaravelho do coração era, verdadeiramente, o "coração de eternidade" do defunto ${ }^{(32)}$.

\section{O simbolismo dualista dos amuletos cardíacos}

Iniciando-se no reinado de Tutmés III ou de Amen-hotep II e florescendo plenamente após o período amarniano, durante o qual a simbólica do coração parece ter sido sintomaticamente silenciada, as representações do coração subjacentes ao amuleto cordiforme e ao escaravelho do coração foram explicitamente articuladas entre si de modo a criar um jogo dualista, tão caro à mentalidade egípcia. 
Integrados nesta linha, surgem objectos que adicionam de modo cumulativo símbolos associados às características do objecto complementar. A título exemplificativo, certos amuletos cordiformes começaram a integrar representações do escaravelho, quer na sua totalidade, quer parcialmente através da representação dos élitros do coleóptero. Esta tendência também se registou nos escaravelhos do coração, cuja base começou a ser esculpida com a forma do amuleto cordiforme. Esta tendência de assimilação de características de outros amuletos é, de resto, bem conhecida na produção de amuletos egípcios e atesta um esforço de maximização do potencial mágico do objecto através da acumulação de símbolos que, de uma forma ou de outra, se relacionam entre si. O fenómeno atinge uma proporção diferente quando esta justaposição deu lugar a uma articulação tão perfeitamente conjugada que, na realidade, se torna impossível saber se estamos perante uma ou outra categoria de objectos.

Tal é o caso do esplêndido amuleto cardíaco encontrado na múmia de luia, o pai da rainha Tié. O escaravelho, esculpido de forma naturalista, apresenta os élitros e os contornos do corpo do coleóptero cobertos com folha de ouro. Nas suas asas foi redigido um curto hino alusivo à navegação da barca solar. A base é constituída por um grande amuleto cordiforme, maior do que o próprio escaravelho, no verso do qual foi inscrito o capítulo $30 \mathrm{~B}$. Embora o objecto não difira substancialmente de um escaravelho do coração comum, a dimensão excepcionalmente grande da base em forma de amuleto cordiforme leva a que esta configuração predomine sobre todo o conjunto. Objectos desta natureza são o culminar de um processo substitutivo que, ao contrário do processo de convergência aditivo, associa diferentes categorias de amuletos entre si de tal modo que os amuletos resultantes desta combinação não preservam as características básicas dos amuletos originais. De um modo geral, é nesta óptica de cariz substitutivo que deve ser entendida a confecção de grandes amuletos cordiformes produzidos tendo em conta um uso exclusivamente funerário, sobretudo ao longo do período ramséssida. Tais amuletos revelam uma alteração radical do tamanho, cor, peso e simbolismo dos amuletos cordiformes tradicionais.

A associação simbólica entre os dois amuletos relacionados com o coração não nos deve levar a pensar que o simbolismo das duas categorias de objectos era idêntico. Pelo contrário, tal associação simbólica deve ser entendida à luz de uma delimitação simbólica muito clara entre os dois tipos de objectos. A razão para a sua associação 
simbólica prende-se, portanto, com as diferenças da actuação mágica atribuída às duas categorias de objectos.

Importa, portanto, esclarecer o domínio de "aplicação" mágica específico de cada objecto. Para tal, uma vez mais é nas fontes iconográficas que podemos encontrar pistas para a sua definição diferencial, sobretudo nas que combinam, de modo certamente intencional, a configuração dos dois tipos de objectos.

Um bom exemplo da definição "clássica" da função mágica dos dois amuletos relacionados com o coração é observável, por exemplo, na decoração do túmulo de Sennefer (TT 96), onde a função destes amuletos parece estar associada a diferentes fases da reanimação do defunto $^{(33)}$. O escaravelho do coração, claramente representado com a moldura em ouro e a característica cor verde, assinalava, no programa decorativo do túmulo, a reanimação física do morto e enquadrava-se na sequência alusiva à mumificação. $O$ duplo amuleto cordiforme, por outro lado, de pequenas dimensões, feito em ouro e inscrito com a cartela de Amen-hotep II, parece associado aos rituais que concorrem para a restituição total da sua dignidade e identidade.

De resto, estes dados estão em linha com a caracterização que é obtida a partir da análise das práticas de mumificação ou das fontes iconográficas e textuais. Todas as fontes parecem apontar para uma função distinta atribuída aos amuletos relacionados com o coração. Deste modo, o escaravelho do coração estaria associado à mumificação enquanto o duplo amuleto cordiforme, constituindo uma condecoração (real ou osiríaca), assinalava a sabedoria do defunto e a sua integridade moral.

A complementaridade entre estes símbolos cardíacos é particularmente visível em certos peitorais ramséssidas ${ }^{(34)}$. Apresentando a forma de um colar usekh, estes objectos possuem as extremidades em formato hieracocéfalo( ${ }^{(35)}$. No centro do peitoral figura um grande escaravelho do coração em alto-relevo, ladeado por duas serpentes sagradas. No verso do peitoral, foi demarcado o contorno do amuleto cordiforme no interior do qual foi redigido o capítulo $30 \mathrm{~B}$. A face do peitoral decorada com o escaravelho situa o âmbito de acção deste amuleto no âmbito da reanimação física do coração, promovido pelas deusas hieracocéfalas que simbolizam Ísis e Néftis. O verso do peitoral, dominado pelo amuleto cordiforme, era centrado na justificação moral do defunto que assegurava a recuperação das funções do coração relacionadas com a identidade e o estatuto social. Objectos como este demonstram que se estabelecia uma acção complementar entre 
o amuleto cordiforme e o escaravelho do coração, os quais asseguravam os poderes do coração no corpo e na identidade, mas também no tempo djet e no tempo neheh, a permanência eterna e o regresso à origem, respectivamente.

O que importa desde já destacar é que cada um dos dois amuletos associados ao coração era visto como um símbolo de todo um conjunto de rituais. O escaravelho do coração simbolizava os rituais de mumificação e representava o renascimento solar do defunto. Por outro lado, o amuleto do coração simbolizava os rituais de justificação. Por seu turno, através de processos aditivos e substitutivos, os amuletos relacionados com o coração foram combinados coerentemente, a fim de expressar a dualidade dos meios pelo qual o coração podia manifestar os seus poderes conectivos após a morte. $\mathrm{O}$ escaravelho do coração, como um símbolo de conectividade corporal, desempenhava um papel central dos rituais de mumificação e era atribuído ao defunto por deusas femininas, como ísis e Néftis. Tinha sobretudo um carácter obstétrico e aludia ao renascimento e à identificação com o Sol nascente, o que representava também a integração do defunto no perpétuo ciclo de morte e renascimento do Sol (o que corresponde à conquista da eternidade no tempo neheh). Por outro lado, o amuleto do coração simbolizava a sabedoria do defunto, a sua identidade perene que, tal como o cadáver de Osíris, devia ser preservada para sempre na dimensão djet da eternidade. Como tal, o amuleto do coração desempenhava um papel central na pesagem do coração e nos rituais da justificação, onde divindades masculinas (como Horsaiset) o atribuíam ao defunto como um símbolo do triunfo da pureza e da sabedoria sobre a morte e a corrupção.

Curiosamente, esta dupla caracterização do coração parece ter sido largamente explorada na iconografia, sobretudo na decoração pictórica dos sarcófagos antropomórficos da XXI dinastia. Aí, o amuleto do coração é geralmente pintado de preto (ou azul escuro) e está inscrito com o nome do defunto antecedido pelo título de Osíris. Outros símbolos osiríacos são abundantes, como o ta-uer, o termo djet, o signo hieroglífico do Ocidente (Amentet), o signo hieroglífico do céu (pet) e até mesmo o nome ou a efígie de Nut. Por meio desses símbolos, o amuleto do coração era representado como a faceta osiríaca do defunto. Por outro lado, o escaravelho solar, imagem plena do renascimento evocado no escaravelho do coração, era representado neste contexto como a imagem de identificação do defunto com Ré, o princípio solar que regia o universo. Assim, no contexto das crenças 
da XXI dinastia, os dois símbolos do coração parecem ter sido identificados com os dois princípios do universo, Osíris e Ré, na sequência de uma longa tradição de especulação religiosa.

Alguns peitorais combinam explicitamente as duas formas entre si. O escaravelho, normalmente com cabeça de carneiro, segura entre as patas traseiras um amuleto do coração, enquanto nas patas dianteiras segura o disco solar ${ }^{(36)}$. O escaravelho criocéfalo constitui, na verdade, uma forma criptográfica de redigir o nome Ré-Atum-Khepri, à qual se reunia o amuleto cordiforme como um símbolo de Osíris ${ }^{(37)}$. A associação entre o amuleto do coração e o escaravelho alado não pressupõe, portanto, uma identificação entre estes dois importantes símbolos. Pelo contrário, neste contexto a dualidade entre o amuleto cordiforme e o escaravelho serve de pretexto para ilustrar a síntese solar-ctónica e a união entre Ré e Osíris. Os dois símbolos da consciência tornavam-se assim na base para a identificação do defunto com as duas facetas do grande deus supremo. $\mathrm{O}$ amuleto cordiforme materializava a faceta osiríaca e ctónica do defunto, ao passo que o escaravelho alado fazia alusão à sua manifestação solar. Nesta perspectiva, o amuleto cordiforme surgia prioritariamente como uma evocação osiríaca (sublinhada por vezes com a representação do totem ta-uer ou do próprio nome de Osíris, Usir) que é frequentemente colocada em relação dinâmica com um símbolo solar (como o ba, o disco solar, a ave benu ou o escaravelho solar). Com estas representações o defunto associava-se ao eterno curso do Sol, ao seu perpetuum mobile, mas também se identificava com o triunfo de Osíris sobre a morte. Estes peitorais são, deste modo, alusivos à ressurreição da consciência do defunto e à sua associação à faceta ctónica e solar do deus universal e testemunham o apogeu da articulação dualista entre os dois símbolos tradicionalmente associados ao coração.

A tendência simbólica que promoveu a fusão dos amuletos relacionados com o coração, quer através de processos substitutivos, quer através de processos aditivos, esmoreceu abruptamente após a XXI dinastia. Na Época Baixa, cada um dos amuletos associados ao coração retoma a identidade que the era própria, reflectindo o esforço de depuração típico da época. Curiosamente, enquanto o escaravelho do coração conservou toda a sua importância como um aspecto central dos equipamentos de múmia, o amuleto do coração regressou à sua concepção minimalista, voltando a ser manufacturado como um pequeno objecto utilizado predominantemente pelos vivos. A produção de grandes e complexas versões do amuleto cordiforme era agora uma anacronia. 


\section{Conclusão}

De uma forma ou outra, como símbolo de vida renascida ou de existência perene no Além, a formulação dos dois amuletos cardíacos enraíza-se profundamente na estrutura cognitiva dualista, típica da cultura egípcia, que vê em "duas coisas" a manifestação de uma totalidade complexa. Na verdade, a língua egípcia não tinha palavras para designar noções abrangentes como "cosmos", "mundo", ou "realidade". A representação da natureza dualista do coração expressava, portanto, as noções relacionadas com a natureza humana, que se manifestava sob uma "forma", kheper, individual, cuja sede era o coração hati, mas que atingia a sua plenitude através da integração cósmica, assegurada graças à revelação da maet no coração $i b$.

Como todas as categorias dualistas do pensamento egípcio, como as Duas Terras ou o céu e a terra, a reflexão sobre a maet é sempre o tema dominante do dualismo. Através do dualismo, o pensamento egípcio expressava a realidade inacabada da criação. As Duas Terras foram criadas no princípio do mundo, mas era o faraó que devia assegurar a manutenção da ordem cósmica e o regresso ao tempo mítico da sua criação. O dualismo caracterizava a ordem cósmica, a maet, como um processo incompleto, sempre em risco face ao seu próprio esvaziamento, que se traduzia no seu oposto, a isefet.

Assim, através de sua formulação dualista, o coração reflectia a mesma natureza essencial que o Egipto e o universo. A vida significava plenitude, conectividade e coesão, enquanto a morte significa esvaziamento, aspectividade e desintegração. Tal como as Duas Terras, também os dois corações formulavam a contínua recriação da vida, graças à conformidade do indivíduo à ordem cósmica. Praticando a maet, o homem interiorizava a ordem cósmica e recriava-se a si mesmo, iniciando um processo que seria decisivo no Além, pois era graças a essa recriação que o defunto poderia ser justificado no tribunal de Osíris (mediante a psicostasia simbolizada no amuleto cordiforme) e renascer identificado com o Sol nascente (simbolizado no escaravelho do coração).

As representações relacionadas com a ordem cósmica são, de resto, nucleares na formulação do próprio amuleto cordiforme. Embora oriundas do contexto da teologia implícita, as flutuações registadas na representação do amuleto cordiforme acusam, com um notável grau de "anacronismo", uma certa "contaminação" da evolução das representações do coração sofrida no plano da teologia explícita. O amuleto 
cordiforme usado pelos príncipes e pelo faraó até ao início da XVIII dinastia reflecte a noção detectada nos textos sapienciais do coração cósmico do faraó, ao passo que o amuleto cordiforme de sabedoria, apanágio da elite aristocrática até ao período amarniano, figura perfeitamente como a materialização do coração ouvinte, que assinalava a obediência ao comando (interior) do faraó. O amuleto cordiforme de justificação, por outro lado, figura como a aplicação no horizonte funerário deste mesmo núcleo de crenças. Já o amuleto cordiforme usado na Época Baixa parece preconizar uma adaptação deste objecto tendo em conta a sua integração no horizonte da piedade pessoal. Assim, mais do que um símbolo de conformidade à ordem maética, o amuleto cordiforme passou a ser usado como um símbolo da manifestação interior do deus pessoal. O coração figurava assim como o templo onde a vontade divina se manifestava.

Tal como se detecta nas fontes literárias enquadradas pelo contexto da teologia explícita, também nas fontes simbólicas, onde imperam as noções inerentes à teologia implícita, o amuleto cordiforme figura, em todas constelações mitológicas em que foi integrado, antes de mais nada como um símbolo de integração cósmica, aludindo à responsabilidade individual na manutenção da maet. No ciclo de Hórus, o amuleto cordiforme simboliza a sabedoria que permitia ao faraó realizar a maet sobre a terra, ao passo que no ciclo de Osíris evocava a virtude e o conhecimento conquistado na vida terrena que permitia ao defunto a sua justificação. No ciclo solar o amuleto cordiforme representava a pureza que facultava ao defunto a regeneração possibilitada pela deusa mãe. Em todas estas constelações divinas, o amuleto cordiforme simboliza o poder conectivo do coração ib que assegura a integração cósmica através da sabedoria e da prática da maet. De resto, o amuleto cordiforme pode realmente ser visto como um hieróglifo ib (F 34) em três dimensões. Uma vez que é também o coração ib a ter prevalência na literatura sapiencial, podemos ver nas constelações mitológicas que justificaram a manufactura dos amuletos cordiformes uma certa continuidade com as representações do coração ib oriundas da teologia explícita. Afinal, em ambos os contextos, o coração ib emerge, tanto nos textos como nas fontes iconográficas, como a dimensão da consciência que facultava a integração cósmica do indivíduo, numa palavra. Também a leitura simbólica do escaraveIho do coração remete, como temos vindo a destacar, para a identificação entre o coração hati e o deus Sol, o responsável último pela (re)criação da ordem cósmica. 
Através da formulação dualista do coração, os dois símbolos cardíacos eram implicitamente identificados com os dois princípios cósmi$\cos$, o deus Sol e a maet, que regiam a recriação do mundo, unindo intrinsecamente a vida humana com os elementos do cosmos onde esta se desenrolava.

A representação dualista do coração patente nas fontes iconográficas contrasta vivamente com as representações que se detectam na literatura sapiencial, onde o coração é representado sobretudo com uma entidade singular. Tal diferença de horizontes não nos parece de todo fortuita e encontra paralelo na própria caracterização de deus no singular, típica das fontes sapienciais. A definição de deus no singular é, na nossa opinião, o motivo pelo qual a formulação do coração no singular foi encorajada neste contexto. As representações do coração, quer iconográficas quer literárias, são portanto, resultantes de uma exploração activa e intencionalizada dos modelos teológicos que Ihes estavam subjacentes. Os textos sapienciais, enquadrados por uma reflexão teológica de carácter explícito, promoveu uma definição singular do coração, por definição mais adaptada à definição de deus no singular, ao passo que os símbolos do coração, sendo enquadrados pelas exigências do ritual características de uma teologia ímplícita, foram articulados de modo dualista. De uma forma ou de outra, as representações sapienciais e iconográficas do coração têm um denominador comum: ambas reconhecem o papel fundamental do coração na manutenção da ordem cósmica, e é precisamente com o intuito de melhor caracterizar essa responsabilidade que o carácter singular ou dualista do coração foi intencionalmente formulado.

Notas

(11. Apresentamos este estudo como uma pequena homenagem à importante actividade editorial da revista Cadmo que tenho a sorte de acompanhar já há cerca de quinze anos, primeiro como leitor e agora também como colaborador, contribuindo precisamente com estudos resultantes da minha pesquisa sobre as representaçōes da noção do coração no antigo Egipto que a revista tem divulgado e valorizado. Idêntico papel tem cumprido na divulgação da actividade científica dos investigadores que, sobretudo em Portugal, desenvolvem os seus estudos no domínio da investigação das civilizaçōes pré-clássicas. Com a abertura recentemente operada a novas áreas de investigação, nomeadamente aos estudos clássicos, a revista Cadmo reforçou o seu papel como fórum de reunião de investigadores, o que beneficia enormemente a investigação e a valorização académica das civilizações da Antiguidade e augura a continuidade do projecto dos seus fundadores, em especial ao Professor Doutor José Nunes Carreira, a quem devemos uma justa homenagem.

(2) A. PIANKOFF, Le "Coeur" dans les Textes Égyptiens depuis l'Ancien jusqu'à la fin du Nouvel Empire, 1930. 
(3) H. BRUNNER, "Herz", in Wolfgang Helck e Wolfhart Westendorf (ed.), Lexikon der Ägyptologie, II, cols 1158-1168; H. BRUNNER, Das hörende Herz. Kleine Schriften zur religions und Geitesgeschichte Ägyptens, 1988.

(4) G. LEFEBVRE, Tableau des Parties du Corps Humain mentionées par les Égyptiens, 1952; J. WALKER, Studies in Ancient Egyptian Anatomical Terminology, 1996; T. BARDINET, Les papyrus médicaux de l'Égypte pharaonique, 1995. Embora elaborado a partir dos "Textos dos Sarcófagos", o trabalho de Rune Nyord apresenta também importantes esclarecimentos acerca das representações anatómicas egípcias. Ver R. NYORD, Breathing Flesh. Conceptions of the Body in the Ancient Egyptian Coffin Texts, 2009.

(5) Nas fontes sapienciais é praticamente indiferente especificar o termo cardíaco utilizado. Tal distinção só se revela necessária quando ambos os termos são mencionados em paralelo.

(6) M. LICHTHEIM, Moral Values in ancient Egypt, 1997. Também em N. SHUPAK, Where wisdom can be found? The Sage's Language in the Bible and in Ancient Egyptian Literature, 1993, e M. LICHTHEIM, Maat in Egyptian Autobiographies and related studies, 1992.

(7) J. ASSMANN, "Zur Geschichte des Herzens im alten Ägypten", Idem (ed.) Die Erfindung des inneren Menschen: Studien zur reliogiösen Anthropologie, 1993, pp. 81-113. Ver também idem, The Mind of Egypt: History and meaning in the time of the pharaohs, 2002, pp. 135-137 e pp. 229-230.

(8) Ver R. SOUSA, "A noção de coração no Egipto faraónico: uma síntese evolutiva", em J. Ramos, L. Araújo, A. Santos (org.), Percursos do Oriente Antigo. Homenagem a José Nunes Carreira, Instituto Oriental da Faculdade de Letras da Universidade de Lisboa, Lisboa, 2004, pp. 529-554.

(9) Ver J. ASSMANN, Search for God in Ancient Egypt, pp. 3-6.

(10) Ver R. SOUSA, Iniciação e Mistério no Antigo Egipto, pp. 95-101.

(11) Neste domínio o trabalho de Michel Malaise sobre os escaravelhos do coração constitui uma notável excepção. Ver M. MALAISE, Les Scarabées de coeur dans l'Égypte Ancienne, 1978.

(12) R. SOUSA, «A simbólica do coração no Antigo Egipto: estudo de antropologia religiosa sobre a representação da consciência", Tese de doutoramento em História, Faculdade de Letras da Universidade do Porto, 2006.

(13) A distinção entre teologia implícita e teologia explícita é um constructo teórico proposto por Jan Assmann. Ver J. ASSMANN, The Search for God in Ancient Egypt, 1984, pp. 163-165.

(14) Ver F. PETRIE, Amulets, 1914.

(15) Ver C. ANDREWS, Amulets of Ancient Egypt, 1998, p. 72. Ver também M. MALAISE, Les Scarabées de Coeur, p. 13 e p. 41.

(16) Ver R. SOUSA, "Os amuletos do coração no antigo Egipto: Tipologia e caracterização", Cadmo 15 (2005), pp. 105-130. Ver também R. SOUSA, "The heart amulet in Ancient Egypt: A typological study", em Goyon, J.-C., Cardin, C., Proceedings of the Ninth International Congress of Egyptologists, Peeters Publishers \& Department of Oriental Studies, Lovaina, Paris: Dudley, 2007, Vol. I, pp. 713-721.

(17) Também por nós designado de «tipo semente" em anteriores publicações. O uso desta tipologia levou-nos porém a considerar a designação de "pêndulo" como mais segura e adequada ao simbolismo do objecto. Veja-se R. SOUSA, "Symbolism and Meaning of Pendulum Heart Amulets", Göttinger Miszellen 221 (2009), Göttingen, pp. 69-79. 
(18) Ver Rogério SOUSA, "The meaning of the heart amulets in Egyptian Art", Journal of the American Research Center in Egypt 43 (2007), Cairo, pp. 59-70. Ver também idem, "O amuleto cordiforme na arte egípcia: as representações humanas", Cadmo 18 (2008), pp. 81-107,

(19) A nossa hipótese alinha-se com a hipótese de Andrzej Niwinski que reconhece em grande parte do programa iconográfico dos sarcófagos tebanos da XXI dinastia, alusões a rituais funerários específicos efectuados no perímetro de Deir el-Bahari. Ver A. NIWINSKI, "Iconography of the $21^{\text {st }}$ dynasty", em Uehlinger (dir), Images as Media: Sources for the cultural history of the Near East and the Eastern Mediterranean (Ist millennium BCE), 2000 , p. 27.

(20) É o caso dos amuletos do coração encimados com cabeça humana e os amuletos do coração com a configuração de um pêndulo, anteriormente referidos.

(21) É seguramente com este significado que o amuleto do coração é representado no peito da esfinge Aker na quinta hora do Livro de Amduat.

(22) Sobre o estudo do escaravelho do coração ver M. MALAISE, Les Scarabées de coeur dans l'Égypte Ancienne, 1978. Sobre os escaravelhos do coração conservados em Portugal ver J. ALMEIDA, e L. ARAÚJO, "Escaravelhos egípcios em Portugal», em Cadmo 19 (2009), pp. 97-130.

(23) É o caso do uso de processos de convergência aditivos ou substitutivos. Ver a este respeito C. MÜLLER-WINKLER, Die Ägyptischen Objekt-Amulette, 1987, p. 217.

(24) Veja-se B. AFFHOLDER-GÉRARD, M.-J. CORNIC, Angers, Musée Pincé: Collections Égyptiennes, 1990, p. 70.

(25) S. QUIRKE, «Two Thirteenth Dynasty Heart Scarabs", JEOL 37 (2001-2002), pp. 31-40.

(26) Ver GABER, H., "Les scarabées de coeur à tête humaine à la lumière d'une variante de la pesée du coeur", in Goyon, J.-C., Cardin, C., Proceedings of the Ninth International Congress of Egyptologists, vol. I, 2007, pp. 743-748.

(27) Ver R. SOUSA, "The cardiac vignettes of the Book of the Dead (Late Period)", em BAEDE 17 (2008), pp. 39-53.

(2e) «(...) cette nature composée du ib, qui est à la fois l'ensemble des conduits-met avec ce qu'ils contiennent (liquides, air animateur), et à la fois nos viscères (simplement des endroits particuliers du ib pour les Égyptiens), a rendu impossible toute représentation dans l'écriture. Ainsi, le mot ib est écrit phonétiquement (il n'a pas d'idéogramme spécifique) et sera représenté par un signe hieroglyphique qui, en fait, est un coeur-haty, c'est-à-dire, la partie du corps avec laquelle il a des relations physiologiques fondamentales", em T. BARDINET, Les papyrus médicaux de l'Égypte pharaonique, 1995, pp. 71-72.

(29) Ver H. BRUNNER, "Das Herz im ägyptischen Glauben", in Das hörende Herz. Kleine Schriften zur Religions und Geistesgeschichte Ägyptens, 1988, p. 17. Ver também A. DE BUCK, «Een groep dodenboekspreuken betreffende het hart", JEOL 9 (1944), p. 17. Para idênticos usos do termo ib veja-se A. PIANKOFF, Le "Coeur" dans les Textes Égyptiens depuis l'Ancien jusqu'à la fin du Nouvel Empire, 1930, p. 40.

(30) Ver A. PIANKOFF, Le "Coeur" dans les Textes Égyptiens depuis l'Ancien jusqu'à la fin du Nouvel Empire, 1930, p. 40.

(31) Versãq francesa em L. ARAÚJO, “La Collection Égyptienne du Museu Nacional Soares dos Reis", em Proceedings of the Seventh International Congress of Egyptologists, Uitgeverij Peeters, Lovaina, 1998, p. 61.

(32) Ver M.-P. VANLATHEM, "Scarabeees de coeur in situ», Cd'É 76 (2001), p. 53. 
(33) A decoração do pilar noroeste da câmara funerária é fundamental na compreensão do papel simbólico atribuído a ambos os objectos. A face oeste do pilar apresenta o escaravelho do coração entre outros objectos funerários, ao passo que a face setentrional do pilar apresenta a lustração de Sennefer adornado com o duplo amuleto cordiforme.

(34) F. THILL, "Un nouveau pectoral-scarabée de coeur a Sai (Soudan)", em Mélanges Offerts a Jean Vercoutter, p. 334.

(35) O colar usekh é uma peça frequente no equipamento funerário egípcio, desempenhando, em geral, uma funçăo protectora, a mesma que desempenham as duas cabeças de falcão, representadas nas suas extremidades, que simbolizam o papel de ísis e Néftis.

(36) Também nos soberbos ataúdes de Pinedjem II e de Nesikhonsu, encontramos, na região do peito, elaboradas composições com um programa simbólico semelhante. No epicentro destas composições está o escaravelho Khepri, erguendo nas patas dianteiras o disco solar, e, nas patas traseiras, o coração. Todas estas composições ilustram a regeneração do disco solar ocorrida no mundo inferior. Ver G. DARESSY, Cachettes royales, $\mathrm{PI}$. XLII- pl. XLV.

(37) Em A. NIWINSKI, "The solar-osirian unity as principle of the theology of the "State of Amun" in Thebes in the XXI dynasty", JEOL 30 (1987-1988), pp. 87-106.

\section{Bibliografia}

Luís Manuel de ARAÚJO, "La Collection Égyptienne du Museu Nacional de Soares dos Reis", em Proceedings of the Seventh International Congress of Egyptologists, Lovaina: Uitgeverij Peeters, 1998, pp. 59-65

Brigitte AFFHOLDER-GÉRARD e Marie-Jeanne CORNIC, Angers, Musée Pincé: Collections Égyptiennes, Paris: Réunion des Musées Nationaux, 1990

Júlia Pereira de ALMEIDA e Luís Manuel de ARAÚJO, “Escaravelhos egípcios em Portugal», em Cadmo, 19 (2009), pp. 97-130

Carol ANDREWS, Amulets of Ancient Egypt, Austin: University of Texas Press, 1998

Jan ASSMANN, The Mind of Egypt: History and meaning in the time of the pharaohs, Cambdrige, Massachusetts, Londres: Harvard University Press, 2002

Jan ASSMANN, "Zur Geschichte des Herzens im alten Ägypten», Idem (ed.), Die Erfindung des inneren Menschen: Studien zur reliogiösen Anthropologie, 1993, pp. $81-113$

Jan ASSMANN, The Search for God in Ancient Egypt, Londres, Ithaca: Cornell University Press, 1984

Thierry BARDINET, Les Papyrus Médicaux de l'Égypte Pharaonique, Paris: Fayard, 1995

Helmut BRUNNER, «Herz", in Wolfgang Helck e Wolthart Westendorf (eds.), Lexikon der Ägyptologie, II, Wiesbaden: Otto Harrassowitz, 1980, cols 1158-1168

Helmut BRUNNER, Das hörende Herz. Kleine Schriften zur religions und Geitesgeschichte Ägyptens, Orbis Biblicus et Orientalis, 15, Göttingen, Friburgo: Vandenheck \& Ruprecht, 1988

Georges DARESSY, Catalogue Général des Antiquités Égyptiennes du Musée du Caire, n.․ 61001-61044: Cercueils des cachettes royales, Cairo, 1909 
Adian DE BUCK, "Een groep dodenboekspreuken betreffende het hart", JEOL, 9 (1944), pp. 9-24

Hanane GABER, "Les scarabées de coeur à tête humaine à la lumière d'une variante de la pesée du coeurn em Goyon, J.-C., Cardin, C., Proceedings of the Ninth International Congress of Egyptologists, vol. I, 2007, pp. 743-748

Gustave LEFEBVRE, Tableau des Parties du Corps Humain mentionées par les Égyptiens, Cairo: IFAO, 1952

Miriam LICHTHEIM, Moral Values in ancient Egypt, Orbis Biblicus et Orientalis, 155, Fribourg, Göttingen: Vandenheck \& Ruprecht, 1997

Miriam LICHTHEIM, Maat in Egyptian Autobiographies and related studies, Orbis Biblicus et Orientalis, 120, Fribourg, Göttingen: Vandenheck \& Ruprecht, 1992

Michel MALAISE, Les Scarabées de coeur dans l'Égypte Ancienne, Monographies Reine Élizabeth, Bruxelas, 1978

Michel MALAISE, "La signification des pendentifs cordiformes dans l'art égyptien", CdÉ, 50 (1975), pp. 105-135

Claudia MÜLLER-WINKLER, Die Ägyptischen Objekt-Amulette, Orbis Biblicus et Orientalis, Series Archaeologica, 5, Fribourg: Vandenheck \& Ruprecht, 1987

Andrzej NIWINSKI, "lconography of the 21st dynasty", in Christoph Uehlinger (dir.), Images as Media: Sources for the cultural history of the Near East and the Eastern Mediterranean (Ist millennium BCE), Fribourg, Göttingen: Vendenhoech \& Ruprecht, 2000, pp. 21-43.

Andrzej NIWINSKI, "The solar-osirian unity as principle of the theology of the "State of Amun" in Thebes in the XXI dynasty", JEOL, 30 (1987-1988), pp. 87-106

Rune NYORD, Breathing Flesh. Conceptions of the Body in the Ancient Egyptian Coffin Texts, Copenhaga: Museum Tusculanum Press, 2009.

William Flinders PETRIE, Amulets, Londres, 1914

Alexandre PIANKOFF, Le "Coeur" dans les Textes Égyptiens depuis l'Ancien jusqu'à la fin du Nouvel Empire, Paris: Librairie Orientaliste Paul Geuthner, 1930

Stephen QUIRKE, "Two Thirteenth Dynasty Heart Scarabs", JEOL, 37 (2001-2002), pp. $31-40$

Nili SHUPAK, Where wisdom can be found? The Sage's Language in the Bible and in Ancient Egyptian Literature, Orbis Biblicus et Orientalis, 130, Fribourg, Göttingen: University Press, Vandenhoeck \& Ruprecht, 1993

André de Campos SILVA, "O problema do livre arbítrio e da intervenção divina na Instrução de Ptah-hotep», Cadmo, 19 (2009), pp. 9-32

Rogério SOUSA, “A função do amuleto cordiforme nas representações funerárias do ritual de purificação no antigo Egipto", Artis, 7-8 (2009), pp. 33-42

Rogério SOUSA, Iniciação e Mistério no Antigo Egipto, Lisboa: Ésquilo, 2009

Rogério SOUSA, «Symbolism and Meaning of Pendulum Heart Amulets", GM, 221 (2009), pp. $69-79$

Rogério SOUSA, "The cardiac vignettes of the Book of the Dead (Late Period)", BAEDE, 17 (2008), pp. 39-53 
Rogério SOUSA, "O amuleto cordiforme na arte egípcia: as representações humanas", Cadmo, 18 (2008), pp. 81-107

Rogério SOUSA, "The heart amulet in Ancient Egypt: A typological study", em Goyon, J.-C., Cardin, C., Proceedings of the Ninth International Congress of Egyptologists, vol. I, Lovaina, Paris: Dudley, Peeters Publishers \& Department of Oriental Studies, 2007, pp. 713-721

Rogério SOUSA, "The meaning of the heart amulets in Egyptian Art", Journal of the American Research Center in Egypt, 43 (2007), Cairo, pp. 59-70

Rogério SOUSA, A simbólica do coração no Antigo Egipto: estudo de antropologia religiosa sobre a representação da consciência, tese de doutoramento em História, policopiada, Porto: Faculdade de Letras da Universidade do Porto, 2006

Rogério SOUSA, "Os amuletos do coração no antigo Egipto: Tipologia e caracterização", Cadmo, 15 (2005), pp. 105-130

Rogério SOUSA, "A noção de coração no Egipto faraónico: uma sintese evolutiva", em Percursos do Oriente Antigo. Homenagem a José Nunes Carreira, Lisboa: Instituto Oriental da Faculdade de Letras da Universidade de Lisboa, 2004, pp. 529-554

Florence THILL, "Un nouveau pectoral-scarabée de coeur a Sai (Soudan)", em Mélanges Offerts a Jean Vercoutter, Paris: Éditions Recherches sur les Civilisations, 1985, pp. 331-341

Marie-Paule VANLATHEM, "Scarabées de coeur in situ", Cd'É 76 (2001), pp. 48-56

James WALKER, Studies in Ancient Egyptian Anatomical Terminology, The Australian Centre for Egyptology, Studies 4, Warstminster: Aris \& Phillips Ltd., 1996 